\title{
Produtividade de grãos e componentes do rendimento da aveia preta (Avena strigosa Schreb.) afetados pela densidade e velocidade de semeadura
}

\author{
Grain yield and yield components of black oat (Avena Strigosa Schreb.) as affected by seeding \\ rate and velocity
}

\author{
Henrique Debiasi ${ }^{I}$ Jorge Dubal Martins ${ }^{\text {II }}$ Evandro Luiz Missio ${ }^{\text {III }}$
}

\section{RESUMO}

Com o objetivo de avaliar a influência da densidade $\left(30,60\right.$ e $90 \mathrm{~kg} \mathrm{ha}^{-1}$ de sementes viáveis) e da velocidade $\left(3,2 ; 5,3 ; 6,9\right.$ e $\left.8,2 \mathrm{~km} \mathrm{~h}^{-1}\right)$ de semeadura na produtividade de grãos e componentes do rendimento de aveia preta (Avena strigosa Schreb.), na região de São Gabriel/RS, sob condições de pastejo intenso, executou-se um experimento em blocos ao acaso e três repetições. Observou-se um menor número de panículas por $\mathrm{m}^{2}$ para as densidades de 30 e $60 \mathrm{~kg}$ $\mathrm{ha}^{-1}$, o que foi compensado pelo maior número de cariopses por panícula, de forma que as produtividades de grãos mais elevadas foram obtidas nestas densidades. As densidades não afetaram significativamente a massa de 1000 cariopses. O número de plantas por $\mathrm{m}^{2}$, a produtividade de grãos e os componentes do rendimento (à exceção do número de cariopses por panícula) não foram influenciados pelas velocidades de semeadura.

Palavras-chave: semeadoras, população de plantas, plantas de cobertura.

\section{ABSTRACT}

A field experiment in randomized blocks with three replications was carried out in São Gabriel, Brazil, to evaluate seeding rate $\left(30,60\right.$ e $90 \mathrm{~kg} \mathrm{ha}^{-1}$ of viable seeds) and velocity (3.2; $5.3 ; 6.9$ e $8.2 \mathrm{~km} \mathrm{~h}^{-1}$ ) effect on grain yield and yield components of black oat (Avena strigosa Schreb.), under intensive cattle grazing. A minor number of panicles per $\mathrm{m}^{2}$ was observed for seeding rates of 30 and $60 \mathrm{~kg} \mathrm{ha}^{-1}$, witch was compensated for the major number of cariopsis per panicle, so that higher grain yields were obtained for these seeding rates. Seeding rates did not affect significantly the 1000 cariopsis weight. Number of plants per $\mathrm{m}^{2}$, grain yield and yield components (exception for number of caripsis per panicle) were not influenced by seeding velocity.

Key words: planters, plant population, cover crops.

\section{INTRODUÇÃO}

A aveia preta (Avena strigosa Schreb.) constitui-se em uma das gramíneas de inverno mais cultivadas no Rio Grande do Sul, em função de características como crescimento rápido, rusticidade, elevada produção de forragem, fácil obtenção de sementes e versatilidade de uso. A produção de sementes raramente ultrapassa os $500 \mathrm{~kg} \mathrm{ha}^{-1} \mathrm{e}$ a sua qualidade é insatisfatória, tanto em termos de poder germinativo quanto de vigor (SCHUCH et al., 2000).

Dentre os fatores ambientais que afetam a produtividade de grãos, encontra-se a captação da radiação solar fotossinteticamente ativa, que pode ser potencializada através da manipulação do arranjo de plantas (ARGENTA et al., 2001). Uma das formas de ajustar o arranjo de plantas engloba a variação na densidade de semeadura, a qual interfere ainda na competição inter e intra-específica por recursos do solo, especialmente água e nutrientes (ALMEIDA \& MUNDSTOCK, 2001; ARGENTA et al., 2001), além de provocar mudanças morfofisiológicas nas plantas (PELTONEN-SAINIO \& JÄIRVINEN, 1995; PELTONEN-SAINIO, 1997; SCHUCH et al., 2000; ARGENTA et al., 2001; ZAGONEL et al., 2002).

A aveia preta é capaz de tolerar variações na população de plantas, dentro de certos limites, devido à sua capacidade de perfilhamento (PELTONENSAINIO \& JÄIRVINEN, 1995; ALMEIDA \& MUNDSTOCK, 2001) e de modificação dos

IPrograma de Pós-graduação em Ciência do Solo, Universidade Federal do Rio Grande do Sul (UFRGS). Avenida Bento Gonçalves, 7712, Bairro Agronomia, 91540-000, Porto Alegre, RS, Brasil. Fone: (51) 3316-6852. E-mail: henridebiasi@yahoo.com.br. Autor para correspondência.

${ }^{\text {II } C e n t r o ~ d e ~ P e s q u i s a ~ d e ~ F o r r a g e i r a s, ~ F u n d a c ̧ a ̃ o ~ E s t a d u a l ~ d e ~ P e s q u i s a ~ A g r o p e c u a ́ r i a ~(F E P A G R O), ~ S a ̃ o ~ G a b r i e l, ~ R S, ~ B r a s i l . ~}$

IIICentro de Pesquisa de Sementes, Fundação Estadual de Pesquisa Agropecuária (FEPAGRO), Júlio de Castilhos, RS, Brasil. 
componentes do rendimento de grãos (PELTONENSANIO, 1997; SCHUCH et al., 2000). Porém, são raros os trabalhos realizados com o objetivo de verificar o comportamento da aveia preta mediante a variação no número de plantas por unidade de área, nas condições da região da Campanha do Rio Grande do Sul, o que possibilitaria a quantificação dos valores limites de população de plantas onde a produção de grãos seria ótima. É importante destacar que o perfilhamento, maior responsável pela plasticidade da aveia preta mediante a variação na população de plantas, depende diretamente das condições edafoclimáticas (PEDREIRA et al., 2001), de forma que a resposta desta planta à densidade de semeadura depende do local considerado. Neste sentido, a capacidade de perfilhamento é inibida por fotoperíodos de longa duração (PELTONENSAINIO \& JÄIRVINEN, 1995), luz com uma baixa relação vermelho/vermelho extremo (ALMEIDA \& MUNDSTOCK, 2001), temperaturas elevadas (MUNDSTOCK, 1999), solos compactados (MEROTTO JUNIOR, 1995) e/ou com baixa fertilidade e disponibilidade de água (MUNDSTOCK, 1999).

Outro aspecto a ser destacado é que, via de regra, os estudos relacionados à densidade de semeadura em aveia preta são implantados através da semeadura manual, seguida de desbaste. Nestas condições, a semeadura é realizada a uma profundidade e com uma distribuição uniforme e adequada das sementes, além de não haver danos mecânicos a estas últimas. Isto não ocorre na semeadura mecanizada, pois a maioria das semeadoras de espaçamento entrelinhas reduzido (fluxo contínuo) não possibilita um controle eficiente de profundidade. Segundo ALVES et al. (2004), sob profundidades de semeadura desuniformes e superiores a $3 \mathrm{~cm}$, o número de perfilhos emitidos e a massa seca da planta principal e dos perfilhos são reduzidos. Da mesma forma, a semeadura é normalmente executada em velocidades altas, o que pode diminuir a quantidade de sementes distribuídas e aumentar a danificação mecânica e a desuniformidade de deposição das mesmas (SILVEIRA, 1992; TOURINO \& DANIEL, 1996).

Assim, o objetivo deste trabalho foi avaliar a influência da densidade e da velocidade de semeadura sobre a produtividade de grãos e os componentes do rendimento da aveia preta, na região da Campanha do Rio Grande do Sul.

\section{MATERIAL E MÉTODOS}

O experimento foi conduzido no Centro de Pesquisa de Forrageiras da FEPAGRO, em São Gabriel/ RS. O local se caracteriza por clima do tipo Cfa (subtropical úmido com verões quentes), segundo a classificação de Koeppen (MORENO, 1961), num ARGISSOLO VERMELHO eutrófico (EMBRAPA, 1999), com um teor de argila de $36 \%$. No momento da semeadura, a umidade gravimétrica era de $238 \mathrm{~g} \mathrm{~kg}^{-1} \mathrm{e}$ a densidade do solo de $1,45 \mathrm{Mg} \mathrm{m}^{-3}$. A área não era cultivada há cinco anos, de forma que a vegetação era semelhante a dos campos nativos da região. Foram executadas duas dessecações, sendo a primeira aos 90 e a segunda aos 27 dias antes da semeadura (DAS), utilizando-se glifosato (forma de sal de amônio) nas doses de, respectivamente, 1,44 e $0,72 \mathrm{~kg} \mathrm{ha}^{-1}$ de ingrediente ativo.

A aveia preta cv. “Comum” foi semeada em 29/05/2003, utilizando-se uma semeadora, equipada com onze linhas de semeadura e com dosadores de semente e adubo dos tipos, respectivamente, rotor acanalado e rotor dentado. O espaçamento entrelinhas foi de $20 \mathrm{~cm}$. As sementes e o adubo foram depositados no mesmo sulco, aberto por sulcador do tipo facão guilhotina, atuando a $7 \mathrm{~cm}$ de profundidade (definida através de anel limitador). As sementes e o adubo deveriam ficar a uma profundidade de aproximadamente $3 \mathrm{~cm}$, já que a sua deposição ocorre quando parte do solo já retornou ao sulco. As sementes foram tratadas com triadimenol (fungicida) e imidaclopride (inseticida), nas doses de, respectivamente, 40 e $60 \mathrm{~g} \mathrm{ha}^{-1}$ de ingrediente ativo.

O experimento constituiu-se num bifatorial com parcelas subdivididas, em blocos ao acaso e três repetições. A largura das parcelas correspondeu a 8,8m (equivalente a 44 linhas de semeadura ou quatro passadas da semeadora) e o comprimento a 70m, totalizando uma área de $616 \mathrm{~m}^{2}$. Cada parcela englobou quatro subparcelas, as quais apresentavam 2,2m de largura (11 linhas de semeadura, correspondente a uma passada da semeadora) e 70m de comprimento. As avaliações foram executadas nas sete linhas centrais de cada subparcela, numa extensão de $30 \mathrm{~m}$, descartando-se $20 \mathrm{~m}$ em cada extremidade. Foram testadas três densidades (30, 60 e $90 \mathrm{~kg} \mathrm{ha}^{-1}$ de sementes viáveis, para atingir, respectivamente, populações de 150, 300 e 450 plantas $\mathrm{m}^{-2}$ ), alocadas nas parcelas principais, e quatro velocidades de semeadura (3,2; 5,3; 6,9; e 8,2 $\mathrm{km} \mathrm{h}^{-1}$ ), distribuídas nas subparcelas.

A adubação de base e de cobertura foi realizada de acordo com os resultados da análise de solo e com as recomendações da COMISSÃO DE FERTILIDADE DO SOLO - RS/SC (1995) para aveia destinada à produção de grãos. Assim, na linha de semeadura, aplicaram-se 225kg ha ${ }^{-1}$ de NPK 05-20-20. Foram executadas ainda duas adubações de cobertura, aos 32 e 85 DAS (11 dias após a realização do pastejo), aplicando-se em cada uma delas $22,5 \mathrm{~kg} \mathrm{ha}^{-1}$ de $\mathrm{N}$ na forma de uréia. A quantidade total de $\mathrm{N}$ aplicada foi 
$25 \mathrm{~kg} \mathrm{ha}^{-1}$ superior à recomendada, em virtude da execução do pastejo. Na primeira adubação de cobertura, aplicou-se também $30 \mathrm{~kg}_{\text {ha-1 }}{ }^{-1}$ de potássio na forma de cloreto, haja vista que a adubação de base não foi suficiente para suprir a quantidade recomendada deste nutriente. A entrada dos animais no experimento, por sua vez, deu-se aos 70 DAS. O pastejo foi intenso, utilizando-se uma carga de $6.800 \mathrm{~kg}$ $\mathrm{ha}^{-1}$ de peso vivo, durante um período de quatro dias. Aos 130 DAS, por ocasião do florescimento, aplicouse o fungicida tebuconazole na dose de $150 \mathrm{~g} \mathrm{ha}^{-1}$ de ingrediente ativo e volume de calda de $150 \mathrm{~L} \mathrm{ha}^{-1}$, para o controle das ferrugens (Puccinia coronata f. sp. avenae e Puccinia graminis $\mathrm{f}$. sp. avenae) e da helmintosporiose (Pyrenophora avenae).

Aos 28 DAS e aos 45 dias após o pastejo (45 DAP), determinou-se o número de plantas por $\mathrm{m}^{2}$, através da contagem das plantas existentes em $2 \mathrm{~m}$ de fileira, sendo este procedimento repetido dezoito vezes por subparcela. O número de panículas por $\mathrm{m}^{2}$ foi quantificado através da contagem das panículas correspondentes às plantas existentes em seis amostras por subparcela, cada uma delas composta por duas fileiras contíguas de $0,55 \mathrm{~m}$ de comprimento. A determinação do número de cariopses por panícula foi realizada mediante a contagem das cariopses presentes em dez panículas, coletadas aleatoriamente em cada subparcela. Para a avaliação da produtividade de grãos, foram coletadas quatro amostras por subparcela, cada uma delas englobando as plantas existentes em $4 \mathrm{~m}$ de fileira. Dessa forma, a área de coleta para a determinação da produtividade totalizou $3,2 \mathrm{~m}^{2}$ por subparcela. Depois de trilhados, os grãos oriundos das amostras de uma dada subparcela foram misturados, pesados e a sua umidade medida. Os valores obtidos foram corrigidos para a umidade de referência de $13 \%$ e transformados em $\mathrm{kg} \mathrm{ha}^{-1}$. Das amostras usadas na determinação da produtividade de grãos, extraiu-se duas subamostras para a quantificação da massa de 1000 cariopses, a qual também foi corrigida para uma umidade de $13 \%$.

A análise estatística foi executada pelo programa SOC - EMBRAPA. Os dados foram submetidos à análise da variância e de regressão, pelo método dos polinômios ortogonais para o fator densidade e dos mínimos quadrados para a velocidade de semeadura. Os modelos foram considerados estatisticamente significativos quando a probabilidade de erro foi igual ou inferior a 0,05 . As variáveis número de plantas e de panículas por $\mathrm{m}^{2} \mathrm{e}$ de cariopses por panícula foram submetidas à transformação raiz quadrada. Esta transformação foi necessária, uma vez que o teste de Lilliefors (CAMPOS, 1979) demonstrou que as variáveis anteriormente citadas não podiam ser analisadas através da distribuição normal. Após a transformação, o mesmo teste indicou que as variáveis se ajustaram à distribuição normal.

\section{RESULTADOS E DISCUSSÃO}

A análise da variância indicou que não houve interação significativa entre os fatores densidade e velocidade de semeadura, para as variáveis determinadas, de forma que a análise de regressão foi executada separadamente para cada fator. Na tabela 1 , são apresentadas as estatísticas descritivas (média e

Tabela 1 - Média geral, coeficientes de variação (CV \%) e probabilidades (P > F) associadas aos modelos de maior significância, para as variáveis medidas, em função da densidade e da velocidade de semeadura. São Gabriel, 2003.

\begin{tabular}{|c|c|c|c|c|c|c|}
\hline \multirow{2}{*}{ Fatores } & \multicolumn{6}{|c|}{ Variáveis } \\
\hline & $\begin{array}{c}\text { Plantas por } \mathrm{m}^{2} \text { aos } \\
28 \mathrm{DAS}^{1}\end{array}$ & $\begin{array}{c}\text { Plantas por } \mathrm{m}^{2} \text { aos } \\
45 \mathrm{DAP}^{2}\end{array}$ & $\begin{array}{l}\text { Panículas por } \\
\mathrm{m}^{2}\end{array}$ & $\begin{array}{c}\text { Cariopses por } \\
\text { panícula }\end{array}$ & $\begin{array}{l}\text { Massa } 1000 \\
\text { cariopses (g) }\end{array}$ & $\begin{array}{l}\text { Produtividade } \\
\quad\left(\mathrm{kg} \mathrm{ha}^{-1}\right)\end{array}$ \\
\hline \multicolumn{7}{|c|}{ Densidade $\left(\mathrm{kg} \mathrm{ha}^{-1}\right)$} \\
\hline $\mathrm{P}>\mathrm{F}^{3}$ & $0,000^{*}$ & $0,000^{*}$ & $0,014^{*}$ & $0,023^{*}$ & $0,356^{\text {n.s. }}$ & $0,013^{*}$ \\
\hline $\mathrm{CV} \%$ & 6,37 & 2,55 & 12,23 & 15,14 & 4,15 & 21,34 \\
\hline \multicolumn{7}{|c|}{ Velocidade $\left(\mathrm{km} \mathrm{h}^{-1}\right)$} \\
\hline $\mathrm{P}>\mathrm{F}^{3}$ & $0,189^{\text {n.s. }}$ & $0,170^{\text {n.s. }}$ & $0,222^{\text {n.s. }}$ & $0,038^{*}$ & $0,013^{*}$ & $0,241^{\text {n.s. }}$ \\
\hline CV \% & 4,57 & 13,33 & 10,49 & 8,34 & 5,59 & 23,55 \\
\hline Média geral & 171 & 113 & 313 & 33 & 19,2 & 1.215 \\
\hline
\end{tabular}

${ }^{1}$ DAS = Dias após a semeadura;

${ }^{2} \mathrm{DAP}=$ dias após o pastejo;

3 * - Modelo estatisticamente significativo a 5\% de probabilidade de erro.

ns - Modelo estatisticamente não significativo. 
coeficiente de variação) para as variáveis quantificadas, bem como as respectivas probabilidades associadas aos modelos testados via análise de regressão.

A população de plantas cresceu linearmente com o aumento da densidade de semeadura, tanto aos 28 DAS, quanto aos 45 DAP (Figura 1). Verifica-se também que as populações de 150,300 e 450 plantas $\mathrm{m}^{-2}$, referentes, respectivamente, às densidades de 30,60 e $90 \mathrm{~kg} \mathrm{ha}^{-1}$ de sementes viáveis, não foram atingidas (Figura 1). Levando-se em consideração a ausência de condições climáticas desfavoráveis durante o período compreendido entre a semeadura e a emergência, aliada à execução de tratamento de sementes contra insetos e fungos, a explicação mais provável para a baixa porcentagem de emergência (ao redor de 57\%) encontra-se relacionada à elevada umidade do solo no momento da semeadura. O facão guilhotina abre um sulco de $7 \mathrm{~cm}$ de profundidade (definida por um limitador), sendo as sementes depositadas no solo por uma abertura na sua parte traseira. Teoricamente, quando as sementes atingem o sulco, parte do solo já retornou ao mesmo, de forma que as sementes são depositadas a uma profundidade de aproximadamente $3 \mathrm{~cm}$. Todavia, devido à elevada umidade, ocorreu espelhamento das paredes do sulco e, ao mesmo tempo, o solo não retornou, o que resultou na deposição das sementes a maiores profundidades e, em conseqüência, a menores valores de emergência de plântulas. Ainda, há evidências de que o fungicida

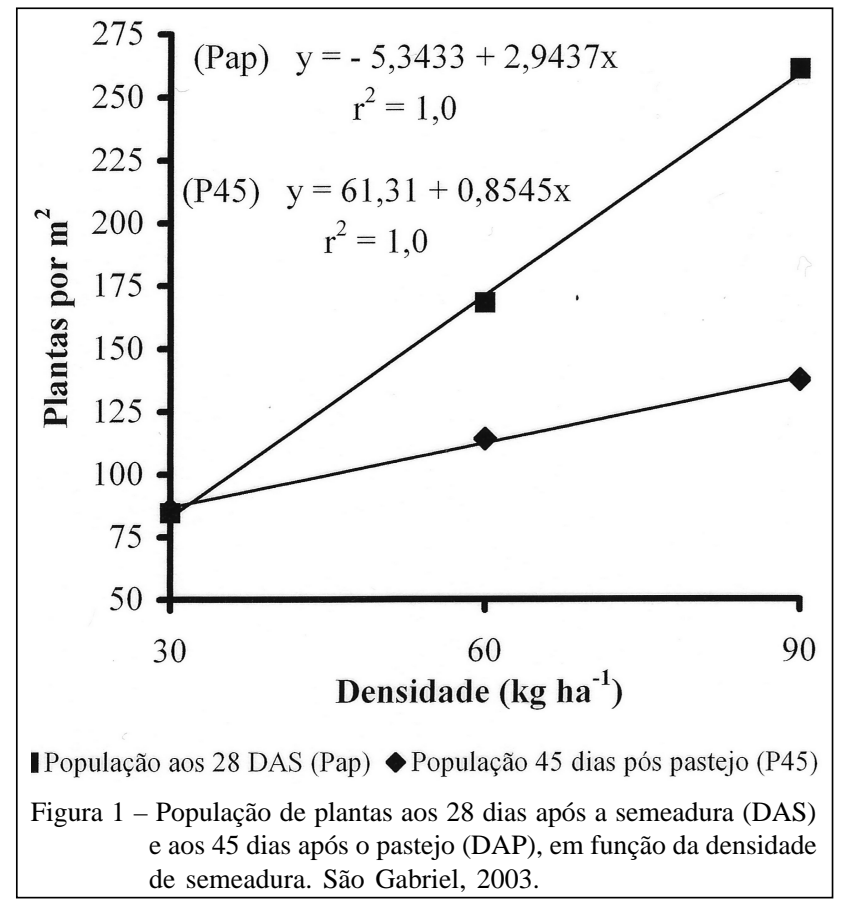

triadimenol, usado neste trabalho, possa reduzir o comprimento do coleóptilo e do mesocótilo, o que foi detectado por SILVA et al. (1993), em trigo e cevada. Assim, a emergência pode ser prejudicada quando do tratamento com esse produto, o que, segundo os referidos autores, foi mais evidente em semeaduras profundas.

Nota-se também que o número médio de plantas por $\mathrm{m}^{2}$ passou de 171 aos 28 DAS para 113 aos 45 DAP (Tabela 1), sendo esse decréscimo observado para as densidades de 60 e $90 \mathrm{~kg} \mathrm{ha}^{-1}$ (Figura 1). Na densidade correspondente a $30 \mathrm{~kg} \mathrm{ha}^{-1}$ de sementes viáveis, a população de plantas permaneceu inalterada; provavelmente, a menor competição intra-específica, típica das menores populações (ARGENTA et al., 2001), implicou plantas mais resistentes ao arranquio pelos animais.

Em relação aos componentes do rendimento, verifica-se, pela figura $2 \mathrm{a}$, que o número de panículas por $\mathrm{m}^{2}$ comportou-se de forma linear e positiva em função do aumento na densidade de semeadura, o que condiz com os dados apresentados por SCHUCH et al. (2000) e por ZAGONEL et al. (2002). Isto significa que a emissão de perfilhos, a qual é maior para os cereais de inverno semeados sob menores densidades (PELTONEN-SAINIO \& JÄIRVINEN, 1995; ALMEIDA \& MUNDSTOCK, 2001; PEDREIRA et al., 2001; ZAGONEL et al., 2002), não foi suficiente para compensar o maior número de plantas observado nas densidades de semeadura mais elevadas. É importante destacar que uma significativa parte dos perfilhos, especialmente os secundários, não emite inflorescência (REIS et al., 1992; ROSSETO \& NAKAGAWA, 2001; ALVES et al., 2004), o que pode ter colaborado para este comportamento. Por outro lado, as plantas de aveia preta tenderam a compensar o menor número de panículas por $\mathrm{m}^{2}$ através do incremento do número de cariopses por panícula, o que é demonstrado na figura 2b. Novamente, a explicação mais provável para este fato encontra-se relacionada à redução na competição intra-específica, característica de densidades menores. A redução no número de grãos por espiga ou panícula com o incremento na densidade de semeadura também é relatada por ZAGONEL et al. (2002), em trigo, e por PELTONEN-SAINIO \& JÄRVINEN (1995) e PELTONEN-SAINIO (1997), em aveia branca. Ao contrário, SCHUCH et al. (2000), comparando três populações (150, 300 e 450 plantas $\mathrm{m}^{-2}$ ) em aveia preta, não encontraram diferenças significativas para o número de cariopses por 


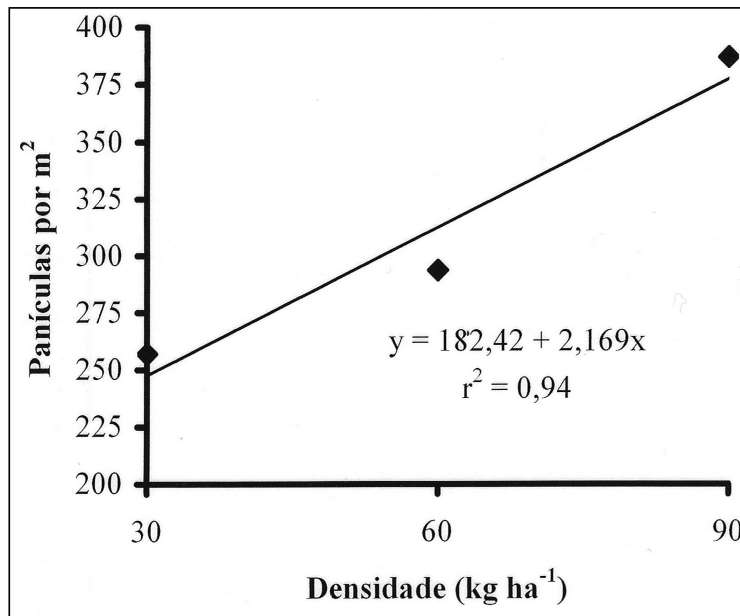

(a)

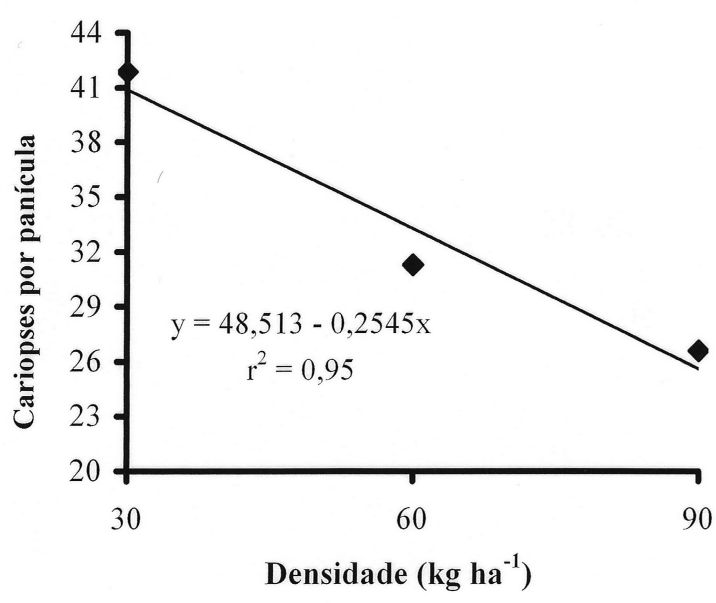

(b)

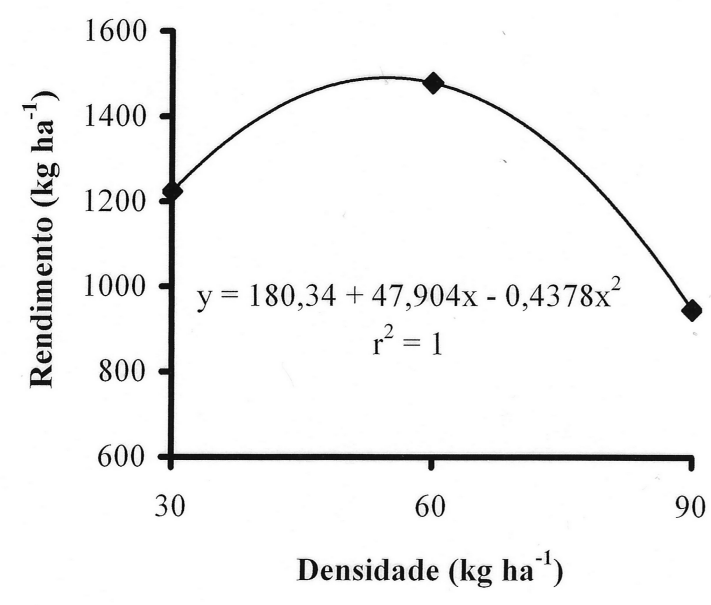

(c)

Figura 2 - Efeito da densidade de semeadura sobre a produtividade de grãos e componentes do rendimento de aveia preta. São Gabriel, 2003. panícula. A massa de 1000 cariopses (Tabela 1) não variou significativamente em relação à densidade de semeadura. No entanto, este componente apresenta resultados diferenciados na literatura, onde ZAGONEL et al. (2002), trabalhando com trigo, e SCHUCH et al. (2000), com aveia preta, concluíram que a massa de 1.000 grãos aumenta com o incremento da densidade de semeadura, enquanto que PELTONEN-SAINIO \& JÄRVINEN (1995), em aveia branca, obtiveram um comportamento inverso.

A produtividade de grãos respondeu de forma quadrática ao incremento nas densidades de semeadura, conforme apresentado na figura 2c. A densidade de $55 \mathrm{~kg} \mathrm{ha}^{-1}$ de sementes viáveis resultou na maior produtividade de grãos (1.491 $\mathrm{kg} \mathrm{ha}^{-1}$ ). Substituindo esta densidade na equação (P45) da figura 1 , verifica-se que a população que proporciona a maior produtividade corresponde a 108 plantas por $\mathrm{m}^{2}$. SCHUCH et al. (2000) obtiveram menores produtividades de grãos de aveia preta para a população mais baixa (150 plantas $\mathrm{m}^{-2}$ ), enquanto que as populações de 300 e 450 plantas $\mathrm{m}^{-2}$ não diferiram entre si. É importante destacar que, no trabalho citado anteriormente, a semeadura foi executada mais tarde, no início do mês de julho, o que, conforme MUNDSTOCK (1999), tende a reduzir o número de afilhos emitidos e a capacidade de compensação da cultura. Além disso, os mesmos autores utilizaram duas cultivares melhoradas ("EMBRAPA 29" e “EMBRAPA 140”), o que também pode afetar o afilhamento (MUDSTOCK, 1999; PEDREIRA et al., 2001). Verifica-se ainda que, entre as densidades de 30 e $60 \mathrm{~kg} \mathrm{ha}^{-1}$, a diferença na produtividade de grãos não foi tão pronunciada quanto a observada entre 60 e $90 \mathrm{~kg} \mathrm{ha}^{-1}$. Sob condições ambientais desfavoráveis, especialmente ventos fortes e chuvas, que proporcionem o acamamento das plantas ao nível do solo (o que não ocorreu neste trabalho), pode-se esperar um desempenho superior da densidade de $30 \mathrm{~kg} \mathrm{ha}^{-1}$, aproximando-se do obtido pela densidade de $60 \mathrm{~kg} \mathrm{ha}^{-1}$, com a vantagem adicional da economia de sementes.

Com relação à velocidade de semeadura, este fator não exerceu influência significativa sobre a população de plantas, tanto aos 28 DAS, quanto aos 45 DAP (Tabela 1). Sob o ponto de vista do funcionamento do mecanismo dosador, este comportamento é condizente com o encontrado por SILVEIRA (1992) que, trabalhando com diferentes velocidades tangenciais no dosador do tipo rotor acanalado helicoidal (semelhante ao usado no presente trabalho), não obteve diferenças significativas na quantidade de sementes de arroz 
distribuídas. A redução na população de plantas aos 45 DAP, em relação aos 28 DAS, não foi uniforme entre as diferentes velocidades de semeadura, variando de $26,5 \%$ a $8,2 \mathrm{~km} \mathrm{~h}^{-1}$ até $43,7 \%$ a $6,9 \mathrm{~km} \mathrm{~h}^{-1}$. Não há, neste trabalho e na literatura consultada, parâmetros que possam justificar tal comportamento. Provavelmente, este resultado esteja relacionado ao pastejo desuniforme entre as subparcelas de cada parcela principal.

Observa-se pela figura 3 que a velocidade de semeadura afetou de maneira quadrática o número de cariopses por panícula. Estes resultados não podem ser explicados levando-se em consideração as variáveis medidas neste trabalho e a bibliografia consultada. A desuniformidade no pastejo, referenciada anteriormente, pode justificar os dados obtidos. Por outro lado, o número de panículas por $\mathrm{m}^{2}$ e a produtividade de grãos não sofreram influência significativa da velocidade de semeadura (Tabela 1 ).

\section{CONCLUSÕES}

Nas densidades de 30 e $60 \mathrm{~kg} \mathrm{ha}^{-1}$, o menor número de panículas por $\mathrm{m}^{2}$, em relação à densidade de $90 \mathrm{~kg} \mathrm{ha}^{-1}$, foi compensado pelo maior número de cariopses por panícula, de forma que as produtividades mais elevadas foram obtidas nessas densidades.

$\mathrm{O}$ aumento da velocidade de semeadura de 3,6 para $8,2 \mathrm{~km} \mathrm{~h}^{-1}$ não afetou negativamente a população de plantas e a produtividade de grãos de aveia preta, assim como não modificou os componentes do rendimento, à exceção do número de cariopses por panícula.

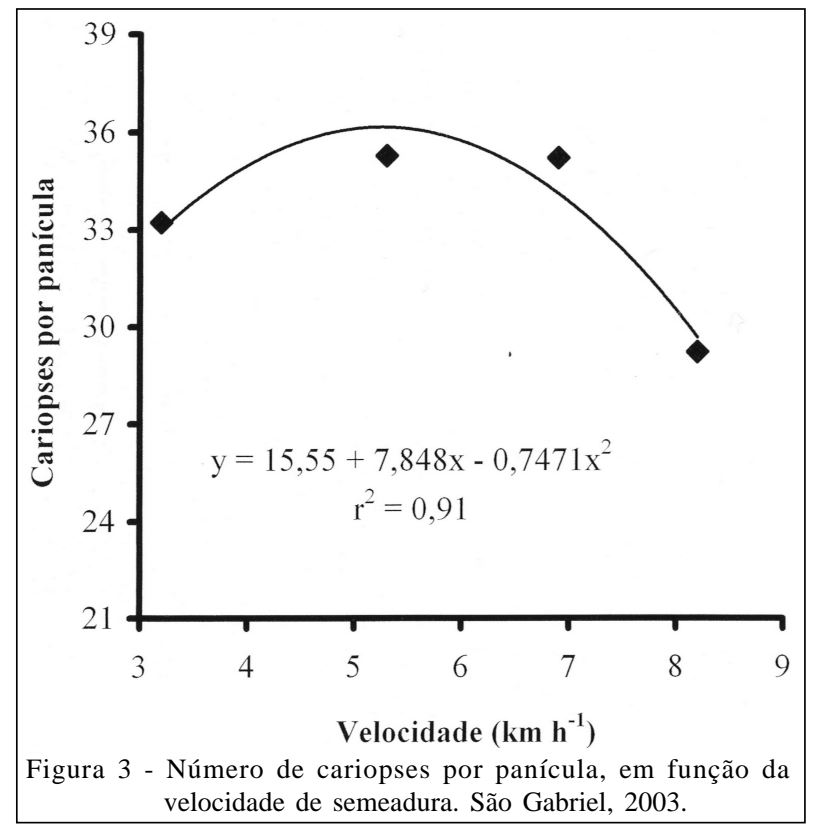

\section{AGRADECIMENTO}

À Fundação Estadual de Pesquisa Agropecuária (FEPAGRO), pelo financiamento da pesquisa.

\section{REFERÊNCIAS}

ALMEIDA, M.L.; MUNDSTOCK, C.M. O afilhamento da aveia afetado pela qualidade da luz em plantas sob competição. Ciência Rural, v.31, n.3, p.393-400, 2001.

ALVES, A.C. et al. Emissão do afilho do coleóptilo em genótipos de aveia e em diferentes condições de estresses e manejo. Ciência Rural, v.34, n.2, p.385-391, 2004.

ARGENTA, G. et al. Arranjo de plantas em milho: análise do estado-da-arte. Ciência Rural, v.31, n.6, p.1075-1084, 2001.

CAMPOS, H. Estatística experimental não-paramétrica. Piracicaba: ESALQ, 1979. 343p.

COMISSÃO DE FERTILIDADE DO SOLO - RS/SC. Recomendações de adubação e calagem para os estados do Rio Grande do Sul e de Santa Catarina. 3.ed. Passo Fundo: SBCS - Núcleo Regional Sul, 1995. 223p.

EMBRAPA. Sistema brasileiro de classificação de solos. Brasília: SPI, 1999. 412p.

MERotTo JÚnior, A. Processo de afilhamento e crescimento de raízes de trigo afetados pela resistência do solo. 1995. 132f. Dissertação (Mestrado em Fitotecnia) Universidade Federal do Rio Grande do Sul, Porto Alegre.

MORENO, J.A. Clima do Rio Grande do Sul. Porto Alegre: Secretaria da Agricultura e Abastecimento, 1961. 41p.

MUNDSTOCK, C.M. Planejamento e manejo integrado da lavoura de trigo. Porto Alegre: ed. do Autor, 1999. 228p.

PEDREIRA, C.G.S. et al. O processo de produção de forragem em pastagens. In: MATTOS, W.R.S. (Ed). A produção animal na visão dos brasileiros. Piracicaba: FEALQ, 2001. p.772-807.

PELTONEN-SAINIO, P.; JÄIRVINEN, P. Seeding rate effects on tillering, grain yield, and yield components of oat at high latitude. Field Crops Research, v.40, p.4956, 1995.

PELTONEN-SAINIO, P. Groat yield and plant stand structure of naked and hulled oat under different nitrogen fertilizer and seeding rates. Agronomy Journal, v.89, p.140-147, 1997.

REIS, R.A. et al. Efeitos de diferentes épocas de colheita sobre a produção de forragem e de sementes de aveia preta. Pesquisa Agropecuária Brasileira, v.27, n.1, p.111117, 1992.

ROSSETTO, C.A.V.; NAKAGAWA, J. Época de colheita e desenvolvimento vegetativo de aveia preta. Scientia Agricola, v.58, n.4, p.731-736, 2001.

Ciência Rural, v.37, n.3, mai-jun, 2007. 
SCHUCH, L.O.B. et al. Vigor de sementes e análise de crescimento de aveia preta. Scientia Agricola, v.57, n.2, p.305-312, 2000.

SILVA, D.B. et al. Efeito do tratamento de sementes sobre a emergência de plântulas de trigo e de cevada em duas profundidades de semeadura. Pesquisa Agropecuária Brasileira, v.28, n.3, p.303-311, 1993.

SILVEIRA, D.R. da. Desempenho de dois mecanismos dosadores de sementes operando em diferentes velocidades e razões de distribuição na semeadura de arroz. 1992. 69f. Dissertação (Mestrado em Engenharia Agrícola, área de concentração em Mecanização Agrícola) Universidade Federal de Santa Maria, Santa Maria.

TOURINO, M.C.C.; DANIEL, L.A. Avaliação da uniformidade de distribuição de sementes de soja (Glycine max (L.) Merril). Ciência e Agrotecnologia, v.20, n.2, p.238-244, 1996.

ZAGONEL, J. et al. Doses de nitrogênio e densidades de plantas com e sem um regulador de crescimento afetando o trigo, cultivar OR-1. Ciência Rural, v.32, n.1, p.25-29, 2002. 